\title{
RESGATANDO IDENTIDADES POR MEIO DA SOLIDARIEDADE E DA LITERATURA: UMA ANÁLISE DAS PERSONAGENS ROSÁLIO E IRENE EM O VOO DA GUARÁ VERMELHA DE MARIA VALÉRIA REZENDE
}

\author{
Fernanda Aquino Sylvestre*
}

\begin{abstract}
Resumo: Maria Valéria Rezende aborda em $O$ voo da guará vermelha o retrato contemporâneo da miséria, não apenas em termos econômicos, mas principalmente morais. Os personagens carecem de identidade e só a recuperam por meio da solidariedade e da literatura, fantasiando, contando histórias. Diante do exposto, o objetivo deste artigo é traçar algumas considerações acerca dos personagens Rosálio da Conceição e Irene, sobretudo no que diz respeito à construção de suas identidades em um contexto miserável, e mostrar como eles as recuperam por meio do contar e do ouvir histórias. Também pretende-se mostrar como os personagens vencem a situação de miséria, através do papel humanizador da literatura.
\end{abstract}

Palavras-chave: Literatura contemporânea; Maria Valéria Rezende; identidade; papel humanizador da literatura.

Abstract: Maria Valeria Rezende discusses in $O$ voo da guará vermelha the contemporary portrait of misery, not only in economic terms, but mostly moral, in which the characters lack their identity and recover it only through solidarity and literature,

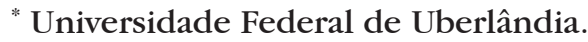


fantasizing, telling histories. Given the above, the purpose of this paper is to outline some considerations about the characters Rosalio and Irene da Conceição, especially with regard to the construction of their identities in a context of widespread poverty, showing how they recover their identities by telling and hearing stories. This article also aims to show how the characters overcome the misery through the humanizing role of literature.

Keywords: Contemporary literature; Maria Valéria Rezende; identity; humanizing role of literature.

Maria Valéria Rezende aborda, em $O$ voo da guará vermelba, o retrato contemporâneo da miséria, não apenas em termos econômicos, mas principalmente morais. Os personagens carecem de reconhecimento identitário e só o recuperam por meio da solidariedade e da literatura. Diante do exposto, é importante esclarecer que o objetivo deste artigo é traçar algumas considerações acerca das personagens Rosálio da Conceição e Irene, sobretudo no que diz respeito à construção de suas identidades em um contexto miserável do Nordeste. Para tanto, inicialmente será traçado um panorama das mudanças ocorridas a partir dos anos 50 na sociedade e consequentemente na arte (incluindo a literatura), mudanças essas que influenciaram a formação da identidade dos sujeitos contemporâneos, como Rosálio e Irene.

A partir dos anos 50, o projeto da modernidade, responsável pelo grande desenvolvimento das sociedades capitalistas dos séculos XIX e XX, pelo fortalecimento do indivíduo burguês, pelo inchaço das grandes cidades e pelo progresso que trouxe adventos tecnológicos começa a se esgotar, a entrar em uma nova fase. A produção e a máquina parecem já ter cumprido o seu papel; instala-se, em seu lugar, o consumo e a informação. Aos poucos, a tecnologia eletrônica de massa (rádio, televisão, computador) foi invadindo o cotidiano das pessoas, saturando-o com informações. O indivíduo passou a lidar com 
signos, com representações da realidade e não com o próprio real. As informações passaram a chegar mais rapidamente e estão presentes ao mesmo tempo nos mais diferentes lugares do mundo. Como as sociedades estão muito ligadas aos mecanismos do mercado mundial, as informações também são sempre uma forma, direta ou indireta, de estimular o consumo. Se a máquina a vapor foi o símbolo da modernidade, a televisão e o computador podem ser tomados como símbolos da contemporaneidade. Se os tempos modernos eram os da energia e da máquina, o atual é aquele que casa, perfeitamente, a mídia e o mercado.

$\mathrm{O}$ indivíduo moderno era alguém isolado na multidão anônima, fragmentado pelas máquinas. $\mathrm{O}$ indivíduo contemporâneo continua fragmentado, isolado na multidão e, além disso, está submetido a um bombardeio de informações que procuram seduzi-lo, informações ligadas principalmente ao consumo - tantas e tão constantes - que acabam tornando-se uma necessidade, pela própria insistência. Dessa maneira, o indivíduo torna-se padronizado, sem identidade definida, ideais ou certezas, vivendo do presente e das informações desse presente.

Após os anos sessenta, as práticas de classe não se traduzem mais em práticas políticas universais, que procuram dar conta da sociedade como um todo. Os partidos de esquerda perdem o conteúdo ideológico e crescem, significativamente, os discursos das minorias, tais como o feminista, o homossexual e o dos negros. Há uma crise da interpretação, causada pelo fim dos monopólios de representação como a família, a Igreja e o Estado.

Assim, as formas de linguagem são quebradas, perde-se a identidade e a unidade em meio à simulação geral. Já não se pode mais pensar no real, mas em simulações da realidade, em visões parciais dentro de um mundo globalizado.

O homem moderno já havia iniciado o seu processo de fragmentação como sujeito; o homem pós-moderno intensifica essa fragmentação por meio do excesso de informações que lhe são expostas e do bombardeio tecnológico que o faz enxergar uma realidade parcial, repleta de ficcionalidades. 
Hall faz considerações acerca das identidades que se modificam desde o iluminismo até o pós-modernismo. Segundo o autor:

Um tipo diferente de mudança estrutural está transformando as sociedades modernas no século XX. Isso está fragmentando paisagens culturais de classe, gênero, sexualidade, etnia, raça e nacionalidade, que, no passado, nos tinha fornecido sólidas localizações como indivíduos sociais. Estas transformações estão também mudando nossas identidades pessoais, abalando a ideia que temos de nós próprios como sujeitos integrados. Esta perda de 'um sentido de si' estável é chamada, algumas vezes, de deslocamento, de descentração do sujeito. (HALL, 2000, p. 9)

Para Hall há três concepções de identidade, a saber: sujeito do iluminismo, sujeito sociológico e sujeito pós-moderno.

O sujeito do iluminismo concebia-se na pessoa humana, no indivíduo centrado na razão, unificado: "o centro essencial do eu era a identidade de uma pessoa" (HALL, 2000, p. 11).

O sujeito sociológico tinha como base a complexidade do mundo moderno emergente e a noção de que "o núcleo interior do sujeito não era autônomo, autossuficiente" (HALL, 2000, p.11). Esse tipo de sujeito percebeu que seu núcleo era formado na sua relação com outras pessoas que mediavam para ele os valores e a cultura. A identidade forma-se, para o sujeito sociológico, na interação: "o sujeito ainda tem um núcleo ou essência interior que é o eu social, mas este é formado e modificado num diálogo contínuo com os mundos culturais 'exteriores' " (HALL, 2000, p.12, grifo do autor) e as identidades que esses mundos oferecem.

O sujeito que possuía identidade fixa está se fragmentando, compondo-se de várias identidades formadas e transformadas continuamente em relação às formas pelas quais somos 
representados ou interpelados nos sistemas culturais que nos rodeiam. A identidade passa a ser definida historicamente e não biologicamente, por isso o sujeito assume identidades diferentes em diferentes momentos.

O sujeito do iluminismo teve suas características focadas nos pressupostos de Descartes, para quem o sujeito moderno nasceu dentro da dúvida e do ceticismo, e de Locke, que dizia ser o indivíduo, possuidor da mesma identidade sempre. À medida que o tempo passou, as sociedades modernas tornaram-se mais complexas e adquiriram "uma forma mais coletiva e social", de acordo com Hall (2000, p.29).

O sujeito social foi sustentado pela biologia de Darwin, em que a razão tinha uma base na natureza e a mente um fundamento no desenvolvimento físico do cérebro humano. O surgimento das novas ciências sociais também contribuiu para a noção de sujeito social. O indivíduo e seus processos mentais tornam-se objeto de estudo e principal preocupação no campo da psicologia.

O sujeito social está associado ao surgimento do modernismo. A figura do indivíduo é a de um ser isolado, alienado, exilado, "colocado contra o pano-de-fundo da multidão ou da metrópole anônima e impessoal” (HALL, 2000, p. 32).

Exemplos desse sujeito podem ser encontrados na obra O pintor da vida moderna, de Baudelaire, cujo personagem constrói sua casa no coração da multidão e se torna o único corpo no meio dela e, em $O$ Processo, de Kafka, com o turista $K$, uma vítima anônima, sem rosto.

O sujeito iluminista apoiava-se na certeza de uma razão autônoma em relação ao mundo exterior. O sujeito social baseava-se na certeza de uma identidade definida pelo contexto social. O sujeito pós-moderno assume-se mais como produto dos discursos sociais, das próprias teorias sobre o homem, dos meios de comunicação, do sistema educacional, do que como ser autônomo capaz de desvendar os mistérios do universo, podendo agir para mudar o mundo (sujeito social), como pensava Descartes. 
Por isso, para os artistas que adotam a perspectiva de um sujeito pós-moderno, a única forma de crítica ou de atuação possível é a intervenção nos próprios sistemas de comunicação, apontando o quanto de ficcionalidade e de ideologia existe em todas as áreas do saber: comunicações, história oficial, entre outras áreas. Mostrar essa perspectiva, na arte, seria contribuir para levar o ser humano a entender essa complexidade do sistema no qual ele está inserido, como faz Maria Valéria Rezende.

$\mathrm{Na}$ perspectiva pós-moderna, os artistas questionam os fundamentos teóricos que abarcam as ideias do sujeito do iluminismo e do sujeito social, fundamentadores das ideias do sujeito moderno e, consequentemente, da modernidade, apontando a dependência entre cultura e sujeito e a conseguinte complexidade desses universos - por isso a impossibilidade de manter as suposições que foram a base da modernidade: sujeito/sociedade, subjetividade/objetividade.

Para justificar o deslocamento do sujeito moderno para o pós-moderno, Hall (2000, p. 38-43) cita cinco fatores. O primeiro deles seria o equívoco de Marx ao considerar que não havia uma essência universal de homem e que essa essência é o atributo de cada indivíduo singular, real. Outro descentramento seria a descoberta de Freud do inconsciente. Para ele, os desejos, a identidade e a sexualidade têm sua origem em processos psíquicos e simbólicos do inconsciente, que não apresentam relações com a razão. Os pressupostos de Freud anulam o conceito do sujeito racional, que possuía uma identidade unificada, proposto por Descartes. Lacan também contribui para o descentramento do sujeito, dizendo que a formação do eu no olbar do outro indica a relação da criança com os sistemas simbólicos fora dela mesma. Esses sistemas externos são a língua, a cultura, a diferença sexual. A identidade, nesse sentido, é algo formado, ao longo do tempo, através de processos inconscientes; ela não é inata.

O terceiro descentramento está baseado nos pressupostos de Saussure que afirma não serem as pessoas, autoras das suas 
afirmações, nem dos significados expressos por elas na língua porque ela é um sistema social preexistente a nós. Como relata Hall: "Falar uma língua não significa apenas expressar nossos pensamentos mais interiores e originais; significa também ativar a imensa gama de significados que já estão embutidos em nossa língua e em nossos sistemas culturais" (HALL, 2000, p. 40).

Derrida (1971), influenciado pelos estudos de Saussure em relação aos significados já existentes na língua (que devem ser considerados pelos falantes), observa que as palavras são multimoduladas, ou seja, não permitem que o produtor fixe o significado de uma forma final, individual. Neste sentido, para Derrida sempre existem significados suplementares, que fazem desaparecer as tentativas de se criar mundos estáveis, fixos.

Foucault (1992), em As palavras e as coisas, aproxima suas ideias das de Derrida ao propor que em cada enunciado não se pode ver uma intenção, uma significação ou a voz reprimida de uma consciência. Para o filósofo, um sentido só pode ser fixado através da diferença de um enunciado com todos os demais, reais ou possíveis, contemporâneos ou não.

Tudo o que se escreve passa por sentidos que não se intencionava transmitir. As palavras não podem, então, representar o que se quer dizer. Não se pode dominar um texto, porque o entretecer de textos e sentidos está fora do controle de quem o interpreta, a linguagem opera por meio do leitor. Um texto se dissolve no outro, está embutido no outro. O produtor apenas cria matérias-primas, deixando aberta ao consumidor a tarefa de recombinar elementos textuais. Se não há como atingir uma representação unificada do mundo porque ela é repressiva e ilusória, fadada a se dissolver, não se deve, em uma perspectiva pós-moderna, tentar-se engajar em um projeto interpretativo e representativo global de textos e do próprio mundo.

O quarto descentramento está localizado nos conceitos de Foucault, principalmente no chamado poder disciplinar, isto é, regulador das populações, do indivíduo e do corpo. Esse poder 
é representado pelas oficinas, escolas, prisões, quartéis, hospitais: os micropoderes. O interessante no pensamento de Foucault, do ponto de vista da história do sujeito moderno, é notar que o poder disciplinar, embora "seja o produto das novas instituições coletivas e de grande escala da modernidade tardia, suas técnicas envolvem uma aplicação do poder e do saber que individualiza ainda mais o sujeito e envolve mais intensamente o seu corpo" (HALL, 2000, p. 43).

Os regimes disciplinares do moderno poder administrativo, segundo Foucault, paradoxalmente, evidenciam que quanto mais coletiva e organizada a natureza das instituições da modernidade tardia, o isolamento, a vigilância e a individualização do sujeito individual tornam-se maiores.

O quinto descentramento citado por Hall é o feminismo, enquanto movimento social e crítica teórica. Esse movimento surgiu durante os anos sessenta, junto com as revoltas estudantis e os movimentos contra-culturais. O quinto descentramento liga-se ao quarto porque o feminismo não deixa de ser uma organização de micropoder.

A partir destas observações, pode-se intuir que a concepção de sujeito fixo do iluminismo desaparece, transformando-o em um sujeito aberto, inacabado, fragmentado, que passa da condição de sujeito moderno a sujeito pós-moderno.

A questão dos descentramentos é relevante para se entender a complexidade e os paradoxos em que se encontra o sujeito contemporâneo e que fará com que este contexto se reflita na literatura atual, inclusive na de Maria Valéria Rezende, por meio das personagens Rosálio e Irene.

Pensando mais especificamente na obra $O$ voo da guará vermelha, dois personagens se destacam por tentarem construir suas identidades, constituindo-se como sujeitos da sociedade contemporânea. Rosálio, pedreiro que de início não possuía nome, e Irene, uma prostituta aidética. 
É interessante notar que os capítulos da obra são nomeados com cores (cinzento e encarnado, verde e negro, roxo e branco, ocre e ouro), que representam o estado das personagens ou os acontecimentos do capítulo. A história tem início com o capítulo nomeado "cinzento e encarnado". Cinzenta é a cor de Rosálio, cuja vida tem sido repleta de agruras, de sofrimentos. Conforme palavras do narrador, a vida desse personagem é tão marcada pela ausência de alegria que seus olhos não encontram cores, por isso, tem "Fome de verdes, de amarelos, de encarnados" (REZENDE, 2005, p. 11).

Rosálio é descrito como um faminto no sentido literal e também metafórico. Possui a "alma" faminta, além de passar fome, ganhar pouco e ser explorado. A fome enquanto necessidade física não constitui a maior preocupação de Rosálio e sim a fome de saber, por isso busca incessantemente alguém que o ensine a finalmente dar sentido aos seus livros guardados no baú, presente de Bugre, o índio que o criou. $O$ aprender a ler faz parte do processo de constituição da identidade do sujeito, excluído por não ter acesso às leis, à cultura, à inserção social. Há tempos o personagem tem andado por caminhos "sendeiros que se redobram sobre si mesmos, enganando aqueles que andam tonteados pelas letras mudas que de todo lado espiam e mangam do homem sem letras" (REZENDE, 2005, p. 12).

A realidade de Rosálio não era só dele, como atesta o narrador, mas de muitos outros excluídos que chegavam nas bandas onde se encontrava o personagem. Sua vida era uma eterna rotina, conforme marca a repetição de ações descritas no seguinte trecho da narrativa:

Comeu feijão, trabalhou, lavou-se, dormiu, comeu feijão, trabalhou, lavou-se, dormiu. Hoje foram-se todos, só ficaram a não cor e o silêncio de cinza neste mundo e em Rosálio medraram a fome de vozes, a fome de encarnados. Lembra-se afinal de uma história que lhe contou o Bugre, enche os bolsos com punhados de brita e sai, a esmo, segurando a alça de corda da caixa de pau 
d'arco que nunca abandona, buscando cores de vida nas ruas vazias. Para onde fugiu a humanidade? sumiu toda? virou lobisomem, boitatá, alma penada, mula-sem cabeça? Rosálio vai deixando um rastro de pedrinhas para marcar o caminho do regresso porque ainda não está pronto para soltar-se outra vez pelo mundo sem conhecer a volta e ainda está devendo o feijão que comeu. (REZENDE, 2005, p. 12)

Por meio do trecho acima, nota-se, ainda, que o personagem sente falta de vida, de humanidade, de solidariedade. Rosálio está preso a seu lugar, porque precisa pagar suas contas, já que deve o feijão que comeu. Também está preso porque se sente só. Quando questiona para onde foi a humanidade, não se pergunta apenas onde estão as pessoas, mas também a solidariedade. $\mathrm{O}$ termo humanidade na sentença em que foi utilizado é ambíguo. Há um tom de ironia ao se supor que as pessoas viraram seres imaginários, como lobisomens e almas penadas, o que reforça o caráter desumano do homem. No excerto também é possível perceber a intertextualidade com o conto de fadas "João e Maria", em que João vai derrubando seixos pelo caminho na esperança de ser encontrado pelo pai. As pedras de Rosálio marcam um caminho de retorno diante da possibilidade de mudar sua condição miserável. O caminho do personagem, embora esteja ligado a sua permanência ao local em que se encontra, mostra uma esperança de que um dia ele consiga superar seu assujeitamento.

Irene apresenta condição semelhante à de Rosálio, mas porque contraíra AIDS e sua condição miserável não lhe permitia um tratamento adequado, sabia que seu futuro seria o cemitério, como relata a própria personagem. Temia a morte apenas porque teria de deixar sua criança com uma senhora que dela já tomava conta. Ao ser apresentada na narrativa, o narrador mostra uma Irene cansada, tentando esquecer seus problemas, uma mulher que não conseguiu um emprego decente e prostituiu-se para sustentar a filha. A condição miserável de Irene é relatada no 
início do primeiro capítulo, quando a voz do narrador se mistura à da personagem:

Irene, cansada, cansada, como custa esforço não pensar em nada!, como custa afastar do pensamento a criança nos braços encarquilhados da velha naquele barraco fincado na lama, o papel amarelo com o resultado do exame, o médico falando, falando, falando, o tempo passando, passando, passando numa correria, quase todo dia já é segunda-feira, ir levar um dinheiro para a velha, ir saber se o remédio prometido chegou, pegar o pacote de camisinhas e ouvir a assistente social lhe dizer que mude de vida. Irene ri, amargo e torto, com uma banda só da boca para não deixar ver a falha dos dentes da outra banda. (REZENDE, 2005, p. 13)

O que aproxima Rosálio e Irene é a miséria de ambos, a dele se justifica na condição de analfabeto, de excluído; a dela, na miséria calcada na falta de dinheiro e de perspectiva de vida, já que sua doença se encontrava em estágio avançado. A aproximação entre os dois é mantida, porque encontram um no outro a possibilidade de vencer suas misérias por meio de um escapismo calcado na fantasia, na literatura oral, no contar e de construírem uma história enquanto sujeitos que seja relevante pelo menos para eles. A solidariedade e o apoio entre Rosálio e Irene é o que os mantém vivos enquanto sujeitos e os faz mudar suas identidades. Obviamente eles não superam por completo a condição de oprimidos perante a sociedade, mas passam a acreditar que podem fazer parte do mundo.

A ligação entre Rosálio e Irene, por meio da solidariedade, tem um poder humanizador, propiciado, sobretudo, pela literatura. A amizade dos dois começa quando Rosálio resolve comparar Irene a uma guará vermelha. A comparação é motivada pelo sentimento de pena que Rosálio sente por ela e pelo sentimento de pena pela ave mencionada. Conta o miserável personagem que uma vez encontrara uma guará vermelha enroscada em um galho de um 
espinheiro e tentara cuidar dela, mas a ave fugira. Rosálio reflete acerca de sua história e acredita que não deveria contar a Irene uma história tão triste, mas ela, já fixada por sua maneira de narrar, exige que ele finalize seu relato. Irene sente-se feliz ao ouvi-lo, alimenta-se de suas palavras e esquece a realidade para viver a fantasia: "Conta, homem, conta mais, é cedo para ir-se embora, nem o dia clareou, enquanto durar a noite, conta, conta para eu sonhar"(REZENDE, 2005, p. 19).

A perspectiva literária de Rosálio e Irene encontra fundamento na voz de Candido para quem a literatura sempre cumpriu um papel essencial na transformação da sociedade, já que, como manifestação artística, permite ao ser humano compreender melhor a realidade que o cerca e a si próprio.

Consoante Antonio Candido (2004, p. 176), a literatura "trazendo em si o que chamamos o bem e o que chamamos o mal, humaniza em sentido profundo porque faz viver".

$\mathrm{E}$, neste mundo cada vez mais competitivo, excludente e repleto de desigualdades sociais, o papel da literatura é fundamental, conforme se pode notar ao se analisar Rosálio e Irene em O voo da guará vermelba.

Candido (2004, p. 186) afirma, ainda, que o direito à literatura deveria constar nos direitos humanos, pois é um bem imprescindível e, como tal, uma necessidade universal:

A literatura corresponde a uma necessidade universal que deve ser satisfeita sob pena de mutilar a personalidade, porque pelo fato de dar forma aos sentimentos e à visão de mundo ela nos organiza, nos liberta do caos e portanto nos humaniza. Negar a fruição da literatura é mutilar a nossa humanidade. Em segundo lugar, a literatura pode ser um instrumento consciente de desmascaramento pelo fato de focalizar as situações de restrição dos direitos, ou de negação deles, como a miséria, a servidão, a mutilação espiritual. Tanto num nível quanto no outro ela tem muito a ver com a luta pelos direitos humanos. 
Em A literatura e a formação do homem, Candido (2002) identifica três funções exercidas pela literatura, as quais, em seu conjunto, denomina de função humanizadora da literatura.

A primeira função é denominada função psicológica, em virtude de sua estreita ligação com a capacidade e necessidade que o ser humano tem de fantasiar. Essa fantasia pode ser presenciada por meio dos devaneios em que o homem se envolve no dia a dia, por meio das novelas, da música, do imaginar o futuro, entre outros modos de se fantasiar. De acordo com Candido, dessas modalidades de fantasia, a literatura talvez seja a mais rica.

Todavia, as fantasias expressas pela literatura, são enraizadas na realidade. É por meio dessa ligação com o real, que a literatura exerce sua segunda função, a função formadora, atuando como instrumento educacional, de formação do homem, já que mostra realidades que a ideologia dominante busca esconder. Consoante Candido (1972, p. 805):

A literatura pode formar; mas não segundo a pedagogia oficial. [...]. Longe de ser um apêndice da instrução moral e cívica, $[. .$.$] , ela age com o impacto indiscriminado da$ própria vida e educa [...]. Dado que a literatura ensina na medida em que atua com toda a sua gama, é artificial querer que ela funcione como os manuais de virtude e boa conduta. E a sociedade não pode senão escolher o que em cada momento lhe parece adaptado aos seus fins, pois mesmo as obras consideradas indispensáveis para a formação do moço trazem frequentemente aquilo que as convenções desejariam banir.

Pode-se notar, pela citação anterior, o poder que a literatura exerce na formação do indivíduo, pois ele pode, por meio dela, desmascarar a ideologia dominante, tendo condições de lutar contra ela quando necessário. Rosálio ao aprender a ler e escrever ganha uma identidade e pode, finalmente, ler seus livros guardados há tanto tempo no baú, além de proporcionar à Irene um sentimento de utilidade, realizando o sonho de infância da personagem de um dia ser professora. 
Rosálio havia sentido na pele as consequências daquele que não conhece as letras e também a necessidade de se ter um documento para poder ser alguém perante a sociedade. A história do personagem está repleta de fantasias, alimentadas pela literatura oral, passada de geração para geração, povoando o imaginário de Rosálio, bem como de todos que tiveram contato com as histórias contadas.

Irene, ansiosa por conhecer melhor Rosálio, pede que conte de onde ele veio. Poeticamente, Rosálio descreve a história do local onde nasceu, uma história mítica, alimentada por seu povo:

O local onde nasci e me criei ficava bem embaixo da Pedras do Pecador, no pé de uma serra sem nome. Diz que aquelas penhas quem botou ali foi um homem muito rico e muito pecador que um dia se arrependeu. Pecou a vida todinha $[. .$.$] até que um dia o arcanjo Miguel lhe$ apareceu, enquanto ele estava dormindo e lhe mostrou sua alma, tão feia, tão má, medonha![...] Então ele ficou arrependido, mas achou que não existia perdão para ele e rezou a Deus que lhe tirasse a vida, porque já não merecia mais viver. Na outra noite, o arcanjo Miguel entrou de novo em seu sonho e lhe disse que só poderia morrer depois que desse aos pobres tudo o que possuía e pedisse perdão a cada um que tinha maltratado. [...] o arcanjo veio mais uma vez e lhe disse que ele ainda tinha outra coisa a fazer [...] mandou que ele carregasse para cima daquela serra uma pedra por cada pecado mortal que cometeu, cada pedra do tamanho do pecado que fosse. [...] pra deixar sinal de que tinha perdoado, Deus fez brotar no meio daquelas pedras um olho d'água que não seca nunca porque é água do perdão de Nosso Senhor [...] Aquele sítio chamou-se de Grota dos crioulos e foi ali que eu nasci. (REZENDE, 2005, p. 25) 
Irene encanta-se com a habilidade de Rosálio de contar histórias de sua própria vida e sonha com elas, alimentando a alma e esquecendo por um momento a dor, por meio da fantasia.

O personagem Rosálio, como já mencionado, nasce e permanece por muito tempo sem identidade definida. Como ele mesmo atesta, nasceu sem nome, nunca teve pai (a mãe engravidara de um homem que passara pela região) e não conheceu a mãe, descrita como uma bela moça que não podia ser mencionada por trazer tristeza a quem seu nome pronunciasse, já que poucos dias após o nascimento de Rosálio se atirara de cima de um morro. Como não tinha um nome, era chamado de "o pequeno" e depois de Nem-Ninguém porque cada vez que chorava, pedindo mais leite, mel, ou angu de fubá, a avó dizia "e vosmecê é nem ninguém para comer mais do que os outros?" (REZENDE, 2005, p. 26).

Rosálio achava sua história triste e, por isso, criou novas versões para ela, acreditando-se diferente de todo povo da Grota, local onde nasceu. Como dizia, "era dali, mas também de qualquer parte por onde meu pai andasse, tinha a pele misturada da cor de toda a gente e quando eu fosse maior e já tivesse aprendido tudo o que há para se saber, havia de ganhar o mundo, que o mundo inteiro era meu e minha cor, minha alforria" (REZENDE, 2005, p. 28).

A identidade de Rosálio, embora ele ainda não tivesse um nome, era múltipla, conforme se pode notar. O personagem acreditava que era como seu povo, mas que também era diferente, agregava características diversas, como é típico do povo brasileiro, era uma mistura do pai e da mãe. Como não tinha uma identidade conhecida, Rosálio tentava imaginá-la. Queria ser do mundo e não apenas ficar enraizado em Grota.

Rosálio foi criado por um bom tempo por Bugre, um índio que dera o seu terceiro nome, Curumim. O nome dado pelo índio era de grande valia para Rosálio, porque era o nome dado por aquele considerado como seu verdadeiro pai. Foi com Bugre que 
Rosálio aprendeu o valor das histórias. Bugre "contava histórias dos livros, contava história da vida, contava história inventada e me ensinava palavras para eu também contar" (REZENDE, 2005, p. 43), atesta Rosálio.

A literatura teve início bem cedo na vida de Rosálio, de maneira informal, pelo contar histórias e perdurou até seu encontro com Irene, ganhando cada vez mais importância em sua vida. A literatura estreitou os laços entre os dois personagens, fazendo Rosálio desejar ficar ao lado de Irene, como se pode notar na passagem em que Irene conta a história de Sherazade. Rosálio, como atesta o narrador, "bem desconfia que ela aprendeu a tramoia para obrigá-lo a ficar, mas não liga, está cansado, vem-lhe o sono e se recosta sobre a colcha cor-de-rosa" (REZENDE, 2005, p. 44). Rosálio acredita que Irene é uma espécie de Sherazade que o prende à casa e à vida dela.

A terceira e última função levantada por Candido, a função social, aborda a identificação do leitor e de seu universo de vida representados na obra literária. Essa função permite ao indivíduo reconhecer a realidade que o cerca quando transposta para o mundo ficcional, da fantasia. Assim ocorre com Rosálio e Irene, que fazem da ficção um modo de superar a condição de miseráveis. Eles não querem apenas uma vida melhor, desejam autoestima, valorização, oportunidade em um mundo onde a desigualdade impera.

Rosálio era ingênuo e bom. Embora miserável, muitas vezes passou por necessidades para proporcionar à Irene uma vida mais digna, não se importando com o fato de ela ser uma prostituta. Irene encontra conforto e sustentação psicológica nas gentilezas do companheiro e sente-se finalmente feliz como atesta a voz do narrador:

Irene mal acredita no que ouve, aquele homem, NemNinguém ou Curumim, seja lá como se chame, quer levá-la a passear!, não tem vergonha de andar com mulher-dama na rua!, já despe o vestido verde, escolhe 
o de cor bonina, quase novo, pouco usado, guardado como promessa de alguma coisa melhor que o dia-a-dia cinzento em que vive há tanto tempo, desde que pegou a doença e foi perdendo a esperança, pinta-se não como sempre, para enganar os fregueses, mas de leve, cores claras como da primeira vez, no dia em que ficou moça e foi para a festa da igreja pensando em ver Romualdo. (REZENDE, 2005, p. 50)

Durante o passeio Irene ouve histórias sobre a infância de Rosálio e escuta como se fosse uma reza ou se fosse um encantamento. Por um momento esquecem de suas duras realidades e fantasiam. Irene diz se sentir transportada para uma floresta enfeitiçada, onde existem fadas e príncipes como os que ela imaginava nas histórias que sua professora de infância contava. No passeio é até capaz de comprar com o dinheiro da prostituição arrecadado pela manhã, algo gostoso e diferente para comer. Com as poucas moedas consegue um saco de pipocas e um cachorroquente que ela e Rosálio dividem como irmãos.

Entretanto, a história que Irene mais deseja saber é a de Rosálio, de como esse nome lhe foi dado. O companheiro, então resolve contá-la. Inicia seu relato, contando que após a morte de Bugre, herdou a tapera onde moravam, mas que essa não era a maior herança recebida e sim os livros. Para ele, as histórias deviam ser contadas para não serem esquecidas. De acordo com Rosálio, só quando ele contava histórias sua alma aquietava. Não via a hora de crescer para ganhar o mundo e aprender a ler. Um dia, no entanto, constroem uma escola na Grota e Rosálio se enche de esperança para aprender a ler e escrever, mas fica sabendo que teria que se matricular e precisava de um nome e documentos. Como não os possuía, desiste de frequentá-la:

[...] embatuquei que não tinha pai nem mãe, nem ninguém que me cuidasse, que a avó já estava caduca, já não dava fé de nada e, a bem dizer, eu não tinha nem nome que prestasse para escrever num caderno, Nem-Ninguém ou 
Curumim, nunca ouvi falar de santo que tivesse um nome assim. Fiquei do lado de fora, ouvindo uma ladainha da qual eu não era parte, nome do pai, Belisário, nome da mãe, Januária. (REZENDE, 2005, p. 61)

Na impossibilidade de frequentar a escola, Rosálio decide assistir às aulas do lado de fora da escola, de cima de um abacateiro que dava para a janela da sala de aula. Na verdade, as poucas aulas dadas pela professora que, sentindo falta de casa, abandona a escola. De acordo com Rosálio a Grota ficou mais pobre sem a escola, porque todos tomaram consciência de sua condição de analfabeto, antes ignorada. Rosálio, no entanto, tinha se encantado pela professora, Rosália e, sem saber que nome escolher para se registrar, copia-lhe futuramente o nome.

A história de Rosálio e Irene tem fim para o leitor com a morte de Irene, mas perdura para Rosálio que não esquece aquela que deu a ele o maior tesouro, a alegria de desvendar as letras, de "compreender o que elas dizem, com elas dizer ideias que na memória escolheu é como tomar cachaça, é como um beijo de amor muitas vezes desejado, que a gente não quer que acabe" (REZENDE, 2005, p. 80).

A solidariedade entre Rosálio e Irene, mediada pela literatura, sugere que Rezende acredita que a pobreza no país é acarretada principalmente pela falta de educação, de leitura, de um ensino decente. Assim como Candido, Rezende parece acreditar que a literatura humaniza, ajuda a vencer barreiras, a construir novas identidades capazes de lutar contra a ideologia dominante e conquistar um espaço no mundo. Nesse sentido, Rezende dá voz, por meio de sua obra literária, aos miseráveis, mostrando que ainda há esperança de uma vida melhor, seja pelo viés da fantasia, seja pela consciência crítica que a literatura é capaz de prover. Rosálio e Irene não vencem a pobreza, mas são cônscios da importância da literatura em suas vidas, não apenas de maneira formal, mas também informal, ligada à oralidade, ao passado retomado em causos e histórias pessoais. Rosálio mostra a Irene 
que sua vida vale a pena, quando diz que ela encontra força como nunca tinha visto em mais ninguém: força de lutar para dar vida ao filho, de lutar contra a doença e, principalmente, para ensinar, salvando-o da cegueira de não saber ler.

Quando a história termina, Rosálio está pronto para ganhar o mundo e repartir com as pessoas seu bem maior, a literatura, conforme relata: $[. .$.$] vou para o meio$ das praças, vou para o meio do mundo contar tudo o que já sei e mais as coisas que eu só posso conhecer quando disser, soltando minhas palavras, sem teto, laje ou telhado por cima de minha cabeça que me separe de Irene, que eu sei que por onde eu for a minha guará vermelha, minha mulher encantada, vai sempre me acompanhar, voando entre o azul e mim, e ela quer ouvir meus contos. (REZENDE, 2005, p. 181)

Spivak (2012) define como excluído aquele cuja voz não pode ser ouvida, precisando da voz de outrem para reivindicar uma posição no mundo. De acordo com a autora, não se pode falar pelo subalterno, entretanto pode-se criar espaços para que ele lute contra a sua condição e se articule para ser ouvido. Rosálio pode ser considerado um excluído aos moldes de Spivak e um exemplo daquele que ganhou voz por meio de outrem, da literatura, garantindo um espaço para fazer reverberar sua voz. 


\section{Referências}

CANDIDO, A. A literatura e a formação do homem. Ciência e Cultura, São Paulo, v. 24, n. 9, p. 803-809, 1972.

CANDIDO, A. O direito à literatura. In: CANDIDO, A. Vários escritos. 5.ed. Rio de Janeiro: Ouro sobre Azul, 2004. p.169- 191.

DERRIDA, J. A escritura e a diferença. São Paulo: Perspectiva, 1971.

FOUCAULT, M. As palavras e as coisas. São Paulo: Martins Fontes, 1992.

HALL, S. A identidade cultural na pós-modernidade. Rio de Janeiro: DP\&A, 2000.

REZENDE, M. V. O voo da guará vermelha. Rio de Janeiro: Objetiva, 2005.

SPIVAK,G. C. Pode o subalterno falar? Belo Horizonte: Ed. UFMG, 2012.

Recebido para publicação em 28 de janeiro de 2013 Aprovado em 20 de março de 2014 